\title{
Clinical and prognostic implications of pretreatment albumin to C-reactive protein ratio in patients with hepatocellular carcinoma
}

Mian-Tao Wu $\mathbf{W}^{1,2+} \mathbb{D}$, Su-Yin He ${ }^{3 \dagger}$, Shu-Lin Chen ${ }^{1,2+}$, Lin-Fang Li ${ }^{1,2}$, Zheng-Qiang He$e^{2}$, Yuan-Ying Zhu ${ }^{2}$, Xia He $\mathrm{He}^{1,2^{*}}$ and Hao Chen ${ }^{1,2^{*}}$

\begin{abstract}
Background: Despite recent advances in the treatments of hepatocellular carcinoma (HCC), the prognosis of HCC patients remains controversial. The purpose of this study was to investigate the prognostic performance of pretreatment albumin to C-reactive protein ratio (ACR) in patients with HCC.

Methods: This study included 409 initially diagnosed HCC patients retrospectively. The optimal cut-off points for distinguishing high and low ACR value was determined by the X-tile software. The chi-squared test was used for comparing the baseline clinicopathologic parameters in different groups and subgroups. The Cox regression with log-rank tests was used to analyze OS and DFS, and Kaplan-Meier curves was used to estimate the prognosis of HCC patients.
\end{abstract}

Results: Patients with lower ACR were significantly correlated with advanced clinical parameters, using a cut-off points of 5.4 (high $A C R, n=236$ vs. low $A C R, n=173$ ). Multivariate analysis demonstrated that ACR was associated with OS $(\mathrm{HR}=0.544,95 \% \mathrm{Cl}: 0.385-0.769, p=0.001)$, with DFS (HR=0.550,95\% Cl: 0.392-0.772, $p=0.001)$. Treatment exposure $(H R=2.191 ; 95 \% C l: 1.533-3.132 ; p<0.001)$, tumor size ( $H R=1.973 ; 95 \% C l: 1.230-3.164 ; p=0.005)$, serum AFP level $(\mathrm{HR}=1.752 ; 95 \% \mathrm{Cl}: 1.277-2.403 ; p=0.001)$, and TNM stage (HR=0.470; $95 \% \mathrm{Cl}: 0.319-2.504 ; p<0.001)$, were independent factors for OS in HCC patients. Treatment exposure (HR=2.244; 95\% Cl: 1.590-3.166; $p<0.001)$, TNM stage (HR $=2.075 ; 95 \% \mathrm{Cl}: 1.436-3.000 ; p<0.001)$, serum AFP level $(\mathrm{HR}=1.819 ; 95 \% \mathrm{Cl}: 1.340-2.469 ; p=0.001)$, tumor size ( $H R=1.730 ; 95 \% \mathrm{Cl}: 1.113-2.689 ; p=0.015)$, and $\mathrm{ACR}(\mathrm{HR}=0.550 ; 95 \% \mathrm{Cl}: 0.392-0.772 ; p=0.001)$ were independent factors for DFS in HCC patients.

Conclusions: Pretreatment ACR is a convenient and useful parameter for HCC patients predicting OS and DFS. Lower ACR was associated with advanced TNM stage, larger tumor size, and a high concentration of AFP. These results may help to design strategies to personalize management approaches among HCC patients.

Keywords: Albumin to C-reactive protein ratio, Hepatocellular carcinoma, Overall survival, Disease-free survival

\footnotetext{
* Correspondence: hexiasysucc@163.com; chenhaosysucc@163.com

${ }^{\dagger}$ Mian-Tao Wu, Su-Yin He, and Shu-Lin Chen contributed equally to this study and share the first authorship.

${ }^{1}$ Sun Yat-sen University Cancer Center, State Key Laboratory of Oncology in

South China, Collaborative Innovation Center for Cancer Medicine,

Guangzhou, China

Full list of author information is available at the end of the article
}

(c) The Author(s). 2019 Open Access This article is distributed under the terms of the Creative Commons Attribution 4.0 International License (http://creativecommons.org/licenses/by/4.0/), which permits unrestricted use, distribution, and reproduction in any medium, provided you give appropriate credit to the original author(s) and the source, provide a link to the Creative Commons license, and indicate if changes were made. The Creative Commons Public Domain Dedication waiver (http://creativecommons.org/publicdomain/zero/1.0/) applies to the data made available in this article, unless otherwise stated. 


\section{Background}

Hepatocellular carcinoma (HCC) is the major histological subtype of primary liver cancer, and is one of the most common causes of cancer-related death worldwide, accounting for 788,000 deaths in 2015 [1]. Due to the initial symptoms of HCC are not obvious, many patients are in advanced stage when they are diagnosed, which leads to a poor prognosis. In the past decades, more and more attention has been paid to the relationship between inflammatory factors and tumors, many inflammationbased prognostic models had been reported in clinical oncology $[2,3]$. Factors such as hepatitis $\mathrm{B}$ or $\mathrm{C}$ virus, aflatoxin, alcoholic or non-alcoholic cirrhosis, and smoking are all associated with the occurrence of HCC. In southeast Asian countries, cirrhosis caused by HBV infection is one of the main risk factors for $\mathrm{HCC}$, from chronic hepatitis $\mathrm{B}$ to cirrhosis, and then to HCC. It has been found that immune inflammatory response is an important pathological process of tumor development, immune status and chronic inflammation play a significant role in promoting tumor recurrence and metastasis, which is closely related to poor prognosis. HCC is characterized by chronic systemic inflammation due to its unique etiological link with chronic hepatitis, which is related with the release of circulating inflammatory cytokines [4]. In recent years, a series of indicators are often reported in the prognosis of HCC, such as platelet / lymphocyte ratio (PLR), inflammation-based index (IBI), neutrophil / lymphocyte ratio (NLR), and the systemic immune-inflammation index [5-8].

C-reactive protein (CRP) is an acute phase protein, secreted by hepatocytes, can reflect the inflammation of the body under the regulation of pro-inflammatory factors [9]. Previous studies have demonstrated that high levels of CRP are associated with poor prognosis in many malignancies, including lung cancer, breast cancer, castration-resistant prostate cancer, gastric cancer, and colorectal cancer [10-14]. Albumin, also synthesized by hepatocytes, can reflect not only the nutritional status, but also the liver function. Albumin, is another important independent prognostic factor for many cancers, including HCC [15]. The decrease in albumin concentration is often caused by progressive weight loss and cachexia. Studies have shown that albumin levels in HCC patients are significantly lower than those in non-HCC patients, which may be related to liver dysfunction, HCC cell growth or liver damage caused by systemic inflammation [16]. It is generally considered that the treatment options are affected by tumor stage and liver function. Serum albumin, as one of the five elements of the Child-Pugh classification of liver function, is associated with the BCLC staging system [17]. The purpose of this study was to investigate the role of albumin to $\mathrm{C}$-reactive protein ratio (ACR) as a significant and independent factor for HCC prognosis, and its relationship with clinical outcomes.

\section{Methods}

\section{Patients}

The current study has enrolled 925 participants from January 2008 to December 2012. There were 356 patients excluded due to non-first admission, 92 patients were metastatic hepatic carcinoma, 22 patients were concurrent with another tumor, 38 patients have received treatments in other hospitals. Eight additional patients were excluded due to incomplete clinical data. Thus, 409 newly diagnosed and untreated HCC patients were finally included. (Fig. 1.) Patient clinical data, including age, gender, diagnosis, smoke exposure, alcohol exposure, family history of cancer, treatment exposure, tumor size, TNM stage, date of the surgery, date of death, hepatitis B surface antigen (HBsAg), alphafetoprotein (AFP), C-reactive protein (CRP), albumin (ALB), alanine aminotransferase (ALT), aspartate aminotransferase (AST), blood platelet (PLT), absolute neutrophil count (NEUT), absolute lymphocyte count (LYMPH), neutrophil-to-lymphocyte ratio (NLR), platelet -to-CRP ratio (PCR), albumin-to-CRP ratio (ACR), and follow-up results were collected and calculated. Clinical staging of HCC was determined by TNM classification system [18]. The inclusion criteria for clinical cases were as follows: 1) have a clear histological or cytological diagnosis of hepatocellular carcinoma, 2) adequate clinicopathological and follow-up data, 3) routine blood examination were performed after admission and without preoperative adjuvant therapy, and 4) staged on the basis of TNM staging system. The exclusion criteria were as follows: 1) concurrent with other tumors or other types of liver cancer, 2) had prior treatments, 3) patients whose pretreatment laboratory data were not available, or without complete clinical data such as the TNM stage.

\section{Ethics statement}

The design of this study was approved by the Sun Yatsen University Cancer Center research ethics committee. All clinical data involved in this study were informed by the patient's consent. The authenticity of this study has been validated by uploading the key raw data onto the Research Data Deposit public platform (www.researchdata.org.cn), with the approval RDD number as RDDA2017000272.

\section{Patient follow-up}

All patients were followed up by telephone, out-patient and medical records after initial treatment. All cases were followed until June 30, 2016. The prognostic endpoints of this study were OS (overall survival) and DFS (disease-free survival). The endpoint of OS was defined as the death from HCC. The end-point of DFS was defined as recurrence or death from any causes. The total 


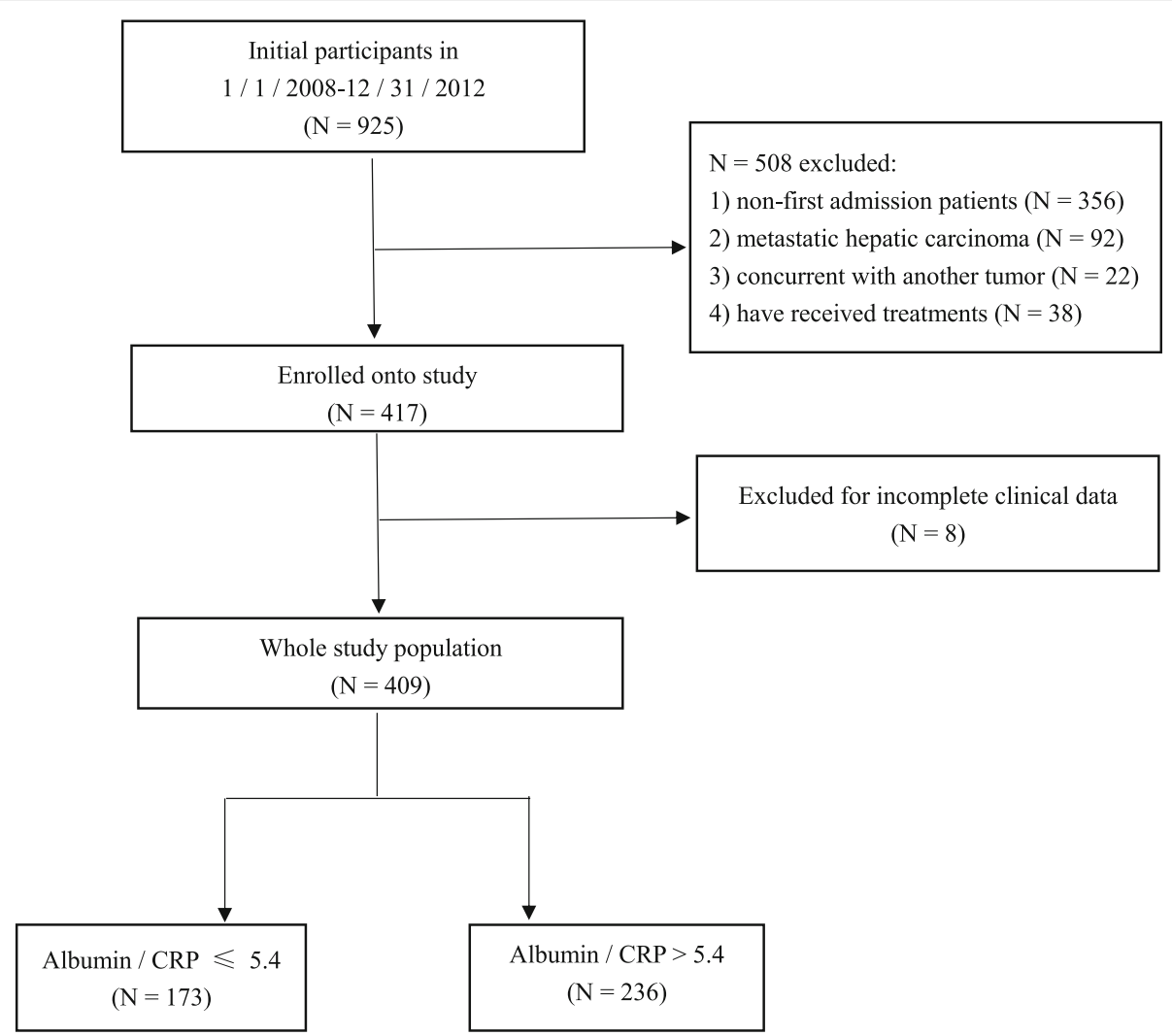

Fig. 1 Flow chart of study participants

survival time was from the diagnosis to the end of the follow-up or at the end of the event. Patients still survive at the time of the last follow-up, or follow-up shedding of any cases for any reasons were defined as censored.

\section{Statistical analysis}

All data were analyzed by SPSS19.0 software (IBM, Chicago, IL, USA). The X-tile software (version: 3.6.1, Copyright Yale University 2003-2005) was applied to determine the optimal cutoff points for the CRP, NLR, PCR, ACR. The baseline clinicopathologic features in different subgroups were compared by Pearson's Chisquare test (Fisher's exact test). Kaplan-Meier analysis was used to compare the overall survival rate and disease-free survival rate between groups or subgroups, and the difference was compared by log-rank test. Cox proportional hazard regression model with univariate and multivariate analysis was used to explore the prognostic factors. A $p<0.05$ was considered significant statistically in this study.

\section{Results}

\section{Definition of cut-off value}

We applied the X-tile software [19] to determine the optimal cut-off value of Albumin / CRP ratio for OS and
DFS, and the patients were classified into low ACR $(<5.4$, $n=173)$ and high ACR groups $(\geq 5.4, n=236)$ (Fig. 2). The results demonstrate that a value of 5.4 had the most significant predictive value for OS $(p<0.0001, \log$-rank chi-square value $=65.1941$, the relative risk of low ACR / high ACR: 2.08 / 1.00). Meanwhile, the optimal cut-off values of CRP, NLR, and PCR were also defined by the Xtile software. The optimal cut-off values of AFP, ALB, ALT, AST, and PLT were defined with medical decision level or medical reference range.

\section{Patient characteristics}

The clinical characteristics and demographics of the 409 HCC cases were shown in Table 1. The majority of the patients included in this study were male $(n=369$, 90.2\%). In the low ACR group, there were 157 patients were males $(38.4 \%)$ and 16 were females $(3.9 \%)$, the median age was 50 (range 24-87) years. Seventy-seven cases $(18.8 \%)$ with smoking history, 56 cases $(13.7 \%)$ had a history of alcohol exposure, and 37 cases $(9.0 \%)$ have a family history of cancer. One hundred and fifty-one patients (36.9\%) with hepatitis B surface antigen positive. While in the high ACR group, 212 patients (51.8\%) were males and 24 (5.9\%) were females, the median age was 53 (range 13-94) years. Ninety-five cases (23.2\%) had a 


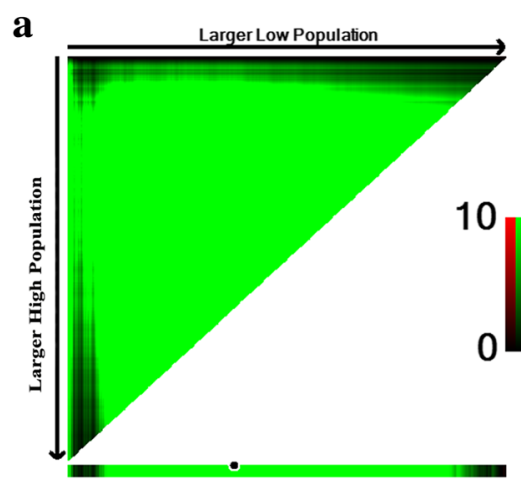

c

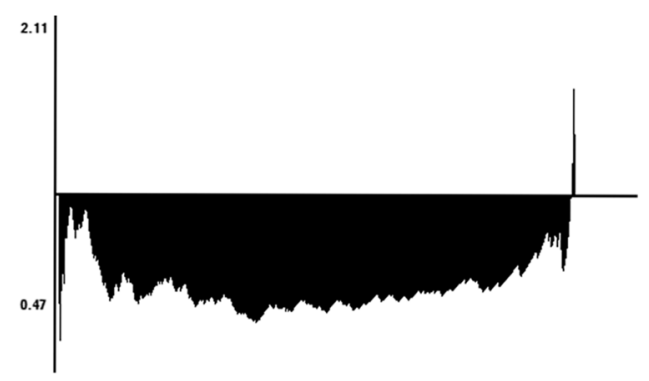

b

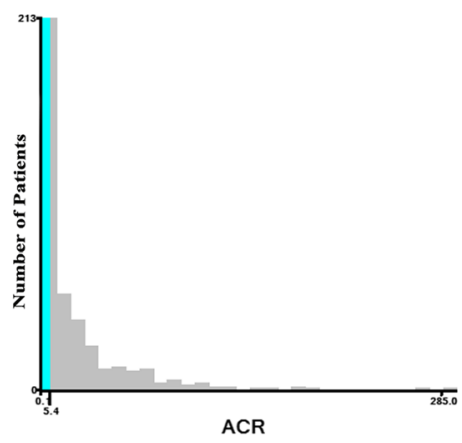

d

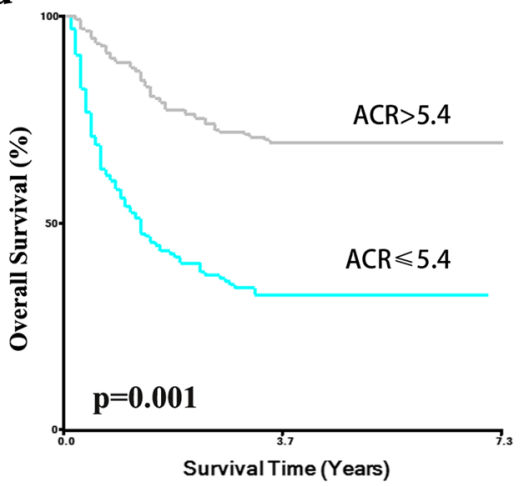

Fig. 2 X-tile plots of the ACR on HCC patients. The plot shows the X2 log-rank values that were created when the cohort was divided into two populations. The cutoff point, which is highlighted by a black/ white circle (a), is demonstrated on a histogram of the entire cohort (b), the relative risks for all cutoff points from low to high (left to right, $x$-axis), are calculated as event in high population / event risk in low population (c), a Kaplan-Meier overall survival curve (d). The preoperative ACR was divided at the optimal cutoff point, as defined by the most significant point on the plot (>5.4 and $\leq 5.4, p=0.001$ )

history of smoking, 69 cases (16.9\%) had a history of alcohol exposure, and 58 cases $(14.2 \%)$ had a family history of cancer. Two hundred and five patients (50.1\%) with hepatitis B surface antigen positive.

When it comes to treatment options, 193 patients (47.2\%) underwent hepatic resection, while the others $(n=216,52.8 \%)$ were given other treatment options, such as transcatheter arterial chemoembolization (TACE, $n=$ $173,42.3 \%$ ), radiofrequency ablation (RFA, $n=23,5.6 \%$ ) and chemotherapy $(n=20,4.9 \%)$. Two hundred and fiftyseven patients $(62.8 \%)$ had larger tumor size ( $\geq 5 \mathrm{~cm}), 178$ patients $(43.5 \%)$ with an advanced stage of HCC. Significant differences can be seen between the two subgroups in treatment exposure (hepatic resection vs. others), in tumor size $(<5 \mathrm{~cm}$ vs. $\geq 5 \mathrm{~cm}$ ), in TNM stage (I, II vs. III, IV), in serum AFP level $(<400 \mathrm{ng} / \mathrm{mL}$ vs. $\geq 400 \mathrm{ng} / \mathrm{mL})$, in serum CRP level $(<6.7 \mathrm{mg} / \mathrm{L}$ vs. $\geq 6.7 \mathrm{mg} / \mathrm{L})$, in serum albumin level $(<40 \mathrm{~g} / \mathrm{L}$ vs. $\geq 40 \mathrm{~g} / \mathrm{L})$, and in platelet / CRP $(<47.8$ vs. $\geq 47.8)$.

\section{Survival analysis}

Among the 409 HCC patients, there were 166 cases died during follow-up, including 165 patients died of HCC, 1 patient died of massive hemorrhage of the digestive tract. One patient had received liver transplantation during follow-up; however, it turns out to die of HCC. The mean OS of the low ACR group was 35.060 months (95\% CI, 29.217-40.904 months) vs. the high ACR group, 65.930 months (95\% CI, 61.447-70.414 months). The 1-, 3 -, and 5-year OS rate were $53.6,34.5$, and $32.7 \%$ for the low ACR group, respectively, and were 88.9, 70.9 and 69.1\% for the high ACR, respectively. The Kaplan-Meier analysis assessed the OS and DFS for all patients of two groups were shown in Fig. 3. The results showed a significant correlation between high ACR group and longer OS $(p<0.0001)$, which indicated that patients with high ALB and low CRP level had a better prognosis.

\section{Univariate and multivariate analyses for OS and DFS}

Univariate and multivariate Cox proportional hazards regression of prognostic factors for OS were shown in Table 2. In the univariate analysis, the significant factors were tumor size $(\mathrm{HR}=4.332$; 95\% CI: 2.896-6.482; $p<0.001)$, TNM stage (HR $=0.211 ; 95 \%$ CI: $0.152-$ $0.293 ; p<0.001)$, treatment exposure $(\mathrm{HR}=3.005 ; 95 \%$ CI: $2.157-4.188 ; p<0.001)$, AFP $(\mathrm{HR}=2.297 ; 95 \% \mathrm{CI}$ : 
Table 1 Patient Demographics and Clinical Characteristics $(n=409)$ (Chi-square test; Fisher's exact test)

\begin{tabular}{|c|c|c|c|c|c|c|}
\hline \multirow[t]{2}{*}{ Characteristics } & \multicolumn{2}{|c|}{$A C R \leq 5.4$} & \multicolumn{2}{|c|}{$A C R>5.4$} & \multirow[t]{2}{*}{$x^{2}$} & \multirow[t]{2}{*}{$P$ value } \\
\hline & No. & $\%$ & No. & $\%$ & & \\
\hline \multicolumn{7}{|l|}{ Age (years) } \\
\hline$\leq 50$ & 89 & 21.8 & 100 & 24.4 & 3.305 & 0.072 \\
\hline$>50$ & 84 & 20.5 & 136 & 33.3 & & \\
\hline \multicolumn{7}{|l|}{ Gender } \\
\hline male & 157 & 38.4 & 212 & 51.8 & 0.096 & 0.867 \\
\hline female & 16 & 3.9 & 24 & 5.9 & & \\
\hline \multicolumn{7}{|l|}{ Smoke exposure } \\
\hline yes & 77 & 18.8 & 95 & 23.2 & 0.741 & 0.418 \\
\hline no & 96 & 23.5 & 141 & 34.5 & & \\
\hline \multicolumn{7}{|l|}{ Alcohol exposure } \\
\hline yes & 56 & 13.7 & 69 & 16.9 & 0.462 & 0.516 \\
\hline no & 117 & 28.6 & 167 & 40.8 & & \\
\hline \multicolumn{7}{|c|}{ Family history of cancer } \\
\hline yes & 37 & 9.0 & 58 & 14.2 & 0.569 & 0.479 \\
\hline no & 136 & 33.3 & 178 & 43.5 & & \\
\hline \multicolumn{7}{|l|}{ Treatment exposure } \\
\hline Hepatic resection & 59 & 14.4 & 134 & 32.8 & 20.596 & $<0.001$ \\
\hline Other & 114 & 27.9 & 102 & 24.9 & & \\
\hline \multicolumn{7}{|l|}{$\mathrm{HBsAg}$} \\
\hline positive & 151 & 36.9 & 205 & 50.1 & 0.016 & 1.000 \\
\hline negative & 22 & 5.4 & 31 & 7.6 & & \\
\hline \multicolumn{7}{|l|}{ Tumor size } \\
\hline$<5 \mathrm{~cm}$ & 21 & 5.1 & 131 & 32.0 & 80.404 & $<0.001$ \\
\hline$\geq 5 \mathrm{~cm}$ & 152 & 37.2 & 105 & 25.7 & & \\
\hline \multicolumn{7}{|l|}{ TNM } \\
\hline | || & 61 & 14.9 & 170 & 41.6 & 54.919 & $<0.001$ \\
\hline III IV & 112 & 27.4 & 66 & 16.1 & & \\
\hline \multicolumn{7}{|l|}{ AFP } \\
\hline$<400 \mathrm{ng} / \mathrm{mL}$ & 93 & 22.7 & 155 & 37.9 & 5.943 & 0.018 \\
\hline$\geq 400 \mathrm{ng} / \mathrm{mL}$ & 80 & 19.6 & 81 & 19.8 & & \\
\hline \multicolumn{7}{|l|}{ CRP } \\
\hline$<6.7 \mathrm{mg} / \mathrm{L}$ & 1 & 0.2 & 228 & 55.7 & 373.600 & $<0.001$ \\
\hline$\geq 6.7 \mathrm{mg} / \mathrm{L}$ & 172 & 42.1 & 8 & 2.0 & & \\
\hline \multicolumn{7}{|l|}{ ALB } \\
\hline$<40 \mathrm{~g} / \mathrm{L}$ & 113 & 27.6 & 67 & 16.4 & 55.244 & $<0.001$ \\
\hline$\geq 40 \mathrm{~g} / \mathrm{L}$ & 60 & 14.7 & 169 & 41.3 & & \\
\hline \multicolumn{7}{|l|}{$\mathrm{ALT}$} \\
\hline$<40 \mathrm{U} / \mathrm{L}$ & 62 & 15.2 & 108 & 26.4 & 4.048 & 0.054 \\
\hline$\geq 40 \mathrm{U} / \mathrm{L}$ & 111 & 27.1 & 128 & 31.3 & & \\
\hline \multicolumn{7}{|l|}{ AST } \\
\hline$<45 \mathrm{U} / \mathrm{L}$ & 80 & 19.6 & 114 & 27.9 & 0.170 & 0.690 \\
\hline$\geq 45 \cup / L$ & 93 & 22.7 & 122 & 29.8 & & \\
\hline
\end{tabular}

Table 1 Patient Demographics and Clinical Characteristics ( $n=409)$ (Chi-square test; Fisher's exact test) (Continued)

\begin{tabular}{|c|c|c|c|c|c|c|}
\hline \multirow[t]{2}{*}{ Characteristics } & \multicolumn{2}{|c|}{$A C R \leq 5.4$} & \multicolumn{2}{|c|}{$A C R>5.4$} & \multirow[t]{2}{*}{$x^{2}$} & \multirow[t]{2}{*}{$P$ value } \\
\hline & No. & $\%$ & No. & $\%$ & & \\
\hline \multicolumn{7}{|l|}{$\overline{\mathrm{PLT}}$} \\
\hline$<100 * 10^{\wedge} 9 / \mathrm{L}$ & 19 & 4.6 & 40 & 9.8 & 2.879 & 0.117 \\
\hline$\geq 100 * 10^{\wedge} 9 / \mathrm{L}$ & 154 & 37.7 & 196 & 47.9 & & \\
\hline \multicolumn{7}{|l|}{ NLR } \\
\hline$<2.3$ & 85 & 20.8 & 125 & 30.6 & 0.587 & 0.484 \\
\hline$\geq 2.3$ & 88 & 21.5 & 111 & 27.1 & & \\
\hline \multicolumn{7}{|l|}{$P C R$} \\
\hline$<47.8$ & 172 & 42.1 & 60 & 14.7 & 222.671 & $<0.001$ \\
\hline$\geq 47.8$ & 1 & 0.2 & 176 & 43.0 & & \\
\hline
\end{tabular}

List of Abbreviations: $H B s A g$ hepatitis B surface antigen, AFP alpha-fetoprotein, $C R P$ C-reactive protein, $A L B$ albumin, $A L T$ alanine aminotransferase, $A S T$ aspartate aminotransferase, $P L T$ platelet, NLR neutrophil-to-lymphocyte ratio, $P C R$ platelet -to-CRP ratio, $A C R$ albumin-to-CRP ratio

1.691-3.122; $p<0.001)$, CRP (HR $=3.378 ; 95 \%$ CI: $2.460-$ 4.640; $p<0.001$ ), ALB (HR $=0.665$; 95\% CI: 0.490-0.902; $p=0.009), \quad$ PCR $\quad(\mathrm{HR}=0.323 ; \quad 95 \% \quad \mathrm{CI}: \quad 0.229-0.457$; $p<0.001)$, and ACR (HR $=0.302$; 95\% CI: 0.221-0.413; $p<0.001$ ). The multivariate analysis (Likelihood ratio forward method), using the above clinical parameters, indicated that tumor size ( $\mathrm{HR}=1.973 ; 95 \% \mathrm{CI}: 1.230-3.164 ; p=0.005)$, TNM stage (HR $=0.470 ; 95 \%$ CI: $0.319-2.504 ; p<0.001)$, treatment exposure $(\mathrm{HR}=2.191 ; 95 \% \quad \mathrm{CI}: \quad 1.533-3.132$; $p<0.001)$, serum AFP level $(\mathrm{HR}=1.752$; $95 \%$ CI: $1.277-$ $2.403 ; p=0.001)$, and ACR (HR $=0.544 ; 95 \%$ CI: $0.385-$ $0.769 ; p=0.001$ ) were independent and significant prognostic factors in HCC patients. Table 3 showed univariate and multivariate Cox proportional hazards regression of prognostic factors for DFS. In the univariate analysis, the significant factors were tumor size $(\mathrm{HR}=3.739 ; 95 \% \mathrm{CI}$ : 2.577-5.426; $p<0.001)$, TNM stage ( $\mathrm{HR}=4.396$; 95\% CI: 3.207-6.026; $p<0.001)$, treatment exposure (HR $=3.029$; 95\% CI: $2.195-$ 4.181; $p<0.001)$, AFP (HR $=2.324 ; 95 \%$ CI: $1.727-3.128$; $p<0.001), \quad \mathrm{CRP} \quad(\mathrm{HR}=3.227 ; 95 \% \quad \mathrm{CI}: 2.376-4.381$; $p<0.001$ ), ALB (HR=0.625; 95\% CI: 0.465-0.841; $p=$ $0.002)$, PCR (HR $=0.340 ; 95 \%$ CI: $0.244-0.473 ; p<0.001$ ), and ACR (HR $=0.315$; 95\% CI: $0.232-0.426 ; p<0.001)$. According to the multivariate analysis using likelihood ratio forward method, treatment exposure $(\mathrm{HR}=2.244 ; 95 \% \mathrm{CI}$ : 1.590-3.166; $p<0.001)$, TNM stage $(\mathrm{HR}=2.075 ; 95 \% \mathrm{CI}$ : 1.436-3.000; $p<0.001$ ), serum AFP level (HR $=1.819$; $95 \%$ CI: $1.340-2.469 ; p=0.001)$, tumor size ( $\mathrm{HR}=1.730 ; 95 \% \mathrm{CI}$ : $1.113-2.689 ; p=0.015)$, and ACR $(\mathrm{HR}=0.550 ; 95 \% \mathrm{CI}$ : $0.392-0.772 ; p=0.001)$ were independent and significant prognostic factors for DFS in HCC patients.

\section{Subgroup analysis for OS and DFS}

Notably, as albumin / CRP ratio was significant associated with other parameters, we therefore performed subgroup 


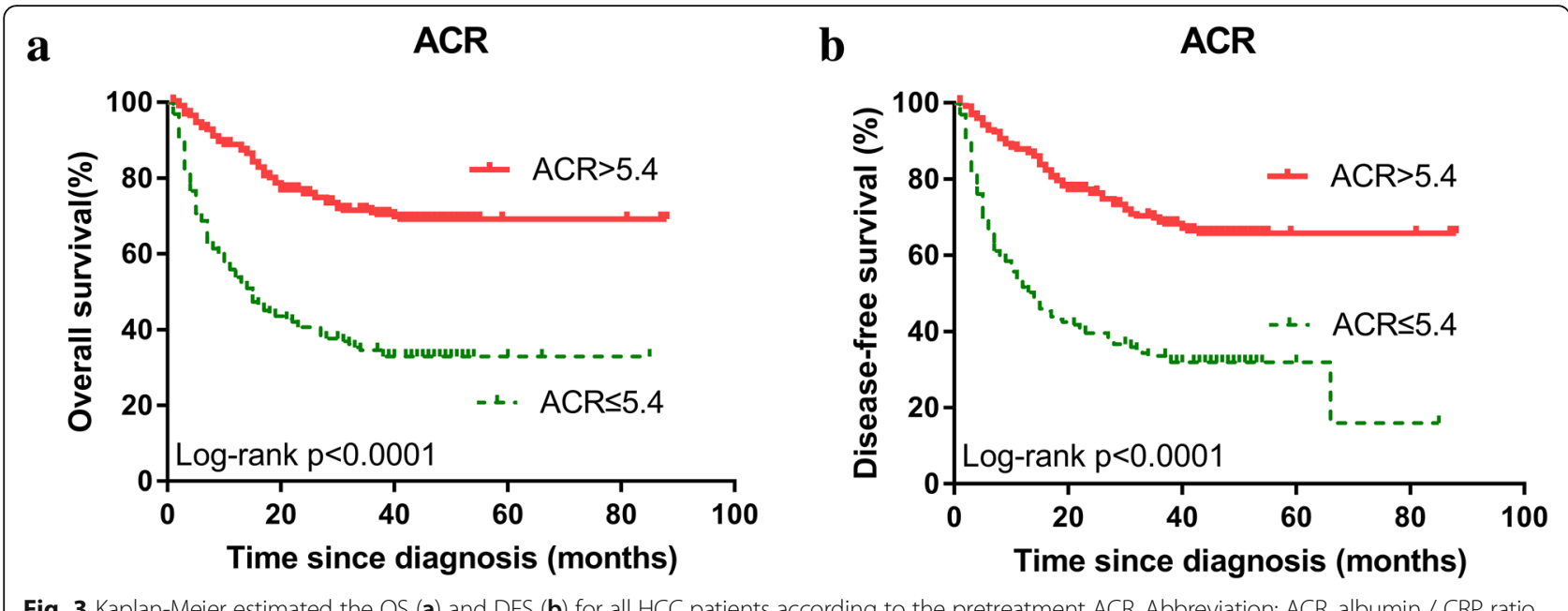

analysis according to tumor size, TNM stage, treatment exposure, serum AFP level, and platelet / CRP (platelet to CRP ratio) (Fig. 4). The 1-, 3-, and 5-year OS rate of the high ACR group were significantly higher than those of the low ACR group in tumor size $<5 \mathrm{~cm}$ subgroup (97.6, $85.0,82.9 \%$ vs. $78.9,47.8,47.8 \%$, respectively; $p<0.0001$ ) (Fig. 4a), in early stage (stage Iand II) subgroup (94.5, 83.5, $81.9 \%$ vs. $74.4,53.2,53.2 \%$, respectively; $p<0.0001$ ) (Fig. 4c), in serum AFP level $<400 \mathrm{ng} / \mathrm{mL}$ subgroup $(95.4,79.8,77.9 \%$ vs. 62.2, 40.8, 39.4\%, respectively; $p<0.0001$ ) (Fig. 4e), and in platelet / CRP $<47.8$ subgroup (79.2, 61.0, $58.7 \%$ vs. 54.1, $34.9,33.2 \%$, respectively; $p=0.0007$ ) (Fig. 4g). The 1-, 3-, and 5 -year DFS rate of the high ACR group were significantly higher than those of the low ACR group in tumor size $<5$ cm subgroup (96.9, 81.6, 78.3\% vs. 78.9, 47.8, 47.8\%, respectively; $p=0.0003$ ) (Fig. 4b), in early stage (stage Iand II) subgroup (93.3, 81.4, 79.1\% vs. $71.8,51.2,51.2 \%$, respectively, $p<0.0001$ ) (Fig. 4d), in serum AFP level $<400 \mathrm{ng} / \mathrm{mL}$

Table 2 Univariate and multivariate Cox proportional hazards regression of prognostic factors for overall survival

\begin{tabular}{|c|c|c|c|c|c|c|}
\hline \multirow[t]{2}{*}{ Characteristics } & \multicolumn{3}{|c|}{ Univariate } & \multicolumn{3}{|c|}{ Multivariate } \\
\hline & $\overline{\mathrm{HR}}$ & $95 \% \mathrm{Cl}$ & $P$ value & $\mathrm{HR}$ & $95 \% \mathrm{Cl}$ & $P$ value \\
\hline Age (years; $\leq 50$ vs. $>50)$ & 0.878 & $0.647-1.192$ & 0.403 & & & \\
\hline Gender (male vs. female) & 1.228 & $0.761-1.980$ & 0.400 & & & \\
\hline Smoke exposure (yes vs. no) & 0.972 & $0.713-1.324$ & 0.857 & & & \\
\hline Alcohol exposure (yes vs. no) & 1.055 & $0.759-1.465$ & 0.751 & & & \\
\hline Family history of cancer (yes vs. no) & 0.924 & $0.641-1.333$ & 0.673 & & & \\
\hline Tumor size $(<5 \mathrm{~cm}$ vs. $\geq 5 \mathrm{~cm})$ & 4.332 & $2.896-6.482$ & $<0.001$ & 1.973 & $1.230-3.164$ & 0.005 \\
\hline TNM (I and II vs. III and IV) & 0.211 & $0.152-0.293$ & $<0.001$ & 0.470 & $0.319-0.693$ & $<0.001$ \\
\hline Treatment exposure (Hepatic resection vs. others) & 3.005 & $2.157-4.188$ & $<0.001$ & 2.191 & $1.533-3.132$ & $<0.001$ \\
\hline HBsAg (positive vs. negative) & 0.820 & $0.536-1.256$ & 0.362 & & & \\
\hline $\operatorname{AFP}\left(\mathrm{ng} / \mathrm{mL}_{i}<400\right.$ vs. $\geq 400$ ) & 2.297 & $1.691-3.122$ & $<0.001$ & 1.752 & $1.277-2.403$ & 0.001 \\
\hline $\mathrm{CRP}\left(\mathrm{mg} / \mathrm{L}_{i}<6.70\right.$ vs. $\left.\geq 6.70\right)$ & 3.378 & $2.460-4.640$ & $<0.001$ & 0.907 & $0.329-2.504$ & 0.851 \\
\hline ALB (g / $\mathrm{L}_{i}<40$ vs. $\left.\geq 40\right)$ & 0.665 & $0.490-0.902$ & 0.009 & 0.960 & $0.691-1.333$ & 0.807 \\
\hline $\operatorname{ALT}\left(U / L_{i}<40\right.$ vs. $\left.\geq 40\right)$ & 1.178 & $0.862-1.610$ & 0.304 & & & \\
\hline AST (U / Li $<45$ vs. $\geq 45)$ & 1.022 & $0.753-1.387$ & 0.889 & & & \\
\hline $\operatorname{PLT}\left({ }^{*} 10^{\wedge} 9 / L_{i}<100\right.$ vs. $\left.\geq 100\right)$ & 1.314 & $0.823-2.097$ & 0.253 & & & \\
\hline $\operatorname{NLR}(<2.3$ vs. $\geq 2.3)$ & 0.963 & $0.709-1.307$ & 0.808 & & & \\
\hline $\mathrm{PCR}(<47.8$ vs. $\geq 47.8)$ & 0.323 & $0.229-0.457$ & $<0.001$ & 0.886 & $0.506-1.551$ & 0.672 \\
\hline $\mathrm{ACR}(\leq 5.4$ vs. $>5.4)$ & 0.302 & $0.221-0.413$ & $<0.001$ & 0.544 & $0.385-0.769$ & 0.001 \\
\hline
\end{tabular}


Table 3 Univariate and multivariate Cox proportional hazards regression of prognostic factors for disease-free survival

\begin{tabular}{|c|c|c|c|c|c|c|}
\hline \multirow[t]{2}{*}{ Characteristics } & \multicolumn{3}{|c|}{ Univariate } & \multicolumn{3}{|c|}{ Multivariate } \\
\hline & $\mathrm{HR}$ & $95 \% \mathrm{Cl}$ & $P$ value & $\mathrm{HR}$ & $95 \% \mathrm{Cl}$ & $P$ value \\
\hline Age (years; $\leq 50$ vs. $>50$ ) & 0.941 & $0.699-1.267$ & 0.690 & & & \\
\hline Gender (male vs. female) & 1.209 & $0.759-1.927$ & 0.424 & & & \\
\hline Smoke exposure (yes vs. no) & 1.021 & $0.757-1.376$ & 0.894 & & & \\
\hline Alcohol exposure (yes vs. no) & 1.184 & $0.865-1.620$ & 0.292 & & & \\
\hline Family history of cancer (yes vs. no) & 0.862 & $0.599-1.239$ & 0.422 & & & \\
\hline Tumor size $(<5 \mathrm{~cm}$ vs. $\geq 5 \mathrm{~cm})$ & 3.739 & $2.577-5.426$ & $<0.001$ & 1.730 & $1.113-2.689$ & 0.015 \\
\hline TNM (I and II vs. III and IV) & 4.396 & $3.207-6.026$ & $<0.001$ & 2.075 & $1.436-3.000$ & $<0.001$ \\
\hline Treatment exposure (Hepatic resection vs. others) & 3.029 & $2.195-4.181$ & $<0.001$ & 2.244 & $1.590-3.166$ & $<0.001$ \\
\hline HBsAg (positive vs. negative) & 0.819 & $0.540-1.242$ & 0.346 & & & \\
\hline $\operatorname{AFP}(\mathrm{ng} / \mathrm{mL} ;<400$ vs. $\geq 400)$ & 2.324 & $1.727-3.128$ & $<0.001$ & 1.819 & $1.340-2.469$ & $<0.001$ \\
\hline $\mathrm{CRP}\left(\mathrm{mg} / \mathrm{L}_{i}<6.70\right.$ vs. $\left.\geq 6.70\right)$ & 3.227 & $2.376-4.381$ & $<0.001$ & 0.863 & $0.318-2.342$ & 0.772 \\
\hline ALB (g / Li $<40$ vs. $\geq 40)$ & 0.625 & $0.465-0.841$ & 0.002 & 0.910 & $0.662-1.251$ & 0.561 \\
\hline $\operatorname{ALT}(U / L ;<40$ vs. $\geq 40)$ & 1.169 & $0.864-1.583$ & 0.312 & & & \\
\hline AST (U / Li $<45$ vs. $\geq 45)$ & 0.974 & $0.724-1.309$ & 0.860 & & & \\
\hline $\operatorname{PLT}\left({ }^{*} 10^{\wedge} 9 / L_{i}<100\right.$ vs. $\left.\geq 100\right)$ & 1.325 & $0.840-2.091$ & 0.226 & & & \\
\hline $\operatorname{NLR}(<2.3$ vs. $\geq 2.3)$ & 0.932 & $0.693-1.253$ & 0.640 & & & \\
\hline PCR (<47.8 vs. $\geq 47.8)$ & 0.340 & $0.244-0.473$ & $<0.001$ & 0.821 & $0.479-1.409$ & 0.474 \\
\hline $\mathrm{ACR}(\leq 5.4$ vs. $>5.4)$ & 0.315 & $0.232-0.426$ & $<0.001$ & 0.550 & $0.392-0.772$ & 0.001 \\
\hline
\end{tabular}

List of Abbreviations: $H B s A g$ hepatitis B surface antigen, AFP alpha-fetoprotein, CRP C-reactive protein, $A L B$ albumin, ALT alanine aminotransferase, $A S T$ aspartate aminotransferase, PLT platelet, NLR neutrophil-to-lymphocyte ratio, $P C R$ platelet -to-CRP ratio, $A C R$ albumin-to-CRP ratio

subgroup (94.7, $77.5,74.7 \%$ vs. $60.2,40.0,38.6 \%$, respectively, $p<0.0001$ ) (Fig. 4f), and in platelet / CRP $<47.8$ subgroup (78.9, 58.2, $55.9 \%$ vs. $51.9,33.8,32.1 \%$, respectively, $p=$ 0.0009) (Fig. 4h). However, Kaplan-Meier analyses and logrank tests demonstrated the OS rate and DFS rate of all HCC patients underwent hepatic resection significantly higher than those accepted other treatment options (both $p<0.0001$ ) (Fig. 5a, b). In hepatic resection subgroup, the 1-, 3-, and 5-year OS rate of the high ACR group were significantly higher than those of the low ACR group (93.8, $77.3,75.2 \%$ vs. $80.5,61.2,61.2 \%$, respectively, $p=0.0229$ ) (Fig. 5c), the 1-, 3-, and 5-year DFS rate of the high ACR group were significantly higher than those of the low ACR group (92.3, 76.5, 74.4\% vs. 77.0, 61.2, 61.2\%, respectively, $p=0.0253$ ) (Fig. 5d).

\section{Discussion}

Prognosis assessment is an important step in HCC management. Although treatment options have been made significant progress, the prognosis of $\mathrm{HCC}$ patients still remains substandard. Any attempts to evaluate prognosis should take the tumor stage, the degree of liver function damage, and the presence of tumor-related symptoms into account [20]. Systemic inflammatory response was considered to be essential factor in the development of malignancies. As one of the acute phase proteins produced by the hepatocytes, CRP has many biological functions, Jun et al. have expounded that a high serum CRP level was associated with larger tumor lesions in patients with HCC [21]. In addition, Kim et al. had indicated that serum CRP levels on the fourth day was the best predictor of postoperative complications after gastrectomy [13]. Albumin is the most important protein in plasma, which represents nutritional status and maintains osmotic pressure. Forrest et al. had revealed that high levels of CRP and hypoproteinemia could be used to evaluate the prognosis of 161 inoperable non-small cell lung cancer patients [22]. Ishizuka et al. had designed their study to assess the prognostic value of CRP / albumin ratio in patients with colorectal cancer, which could predict the survival rate after the colorectal resection [14]. With regard to hepatocellular carcinoma, Kinoshita et al. had retrospectively evaluated $186 \mathrm{HCC}$ patients and revealed that the pretreatment CRP / albumin ratio might be a reliable prognostic factor [23]. However, the albumin / CRP ratio, also considered as the Inflammatory-Nutritional Index (INI), is seldom reported with a prognosis of cancer. The current study firstly investigated the clinical and prognostic implication of albumin / CRP ratio (ACR) in patients with HCC.

In this study, we retrospectively evaluated the albumin / CRP ratio as a prognostic factor in 409 newly diagnosed HCC patients. The results of Cox regression analysis suggest that the pretreatment ACR was an independent factor for $\mathrm{HCC}$ prognosis, high ACR is associated with better 
a

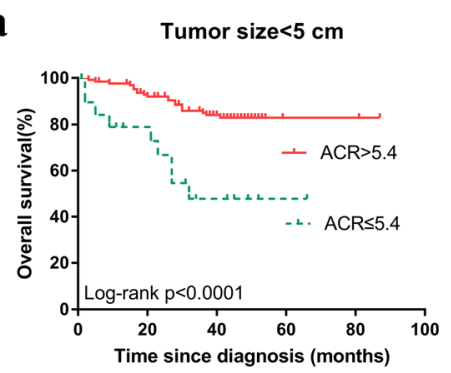

c

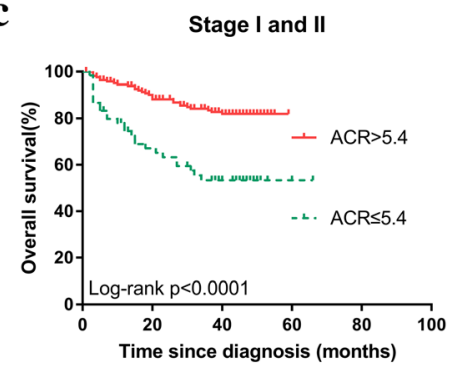

e

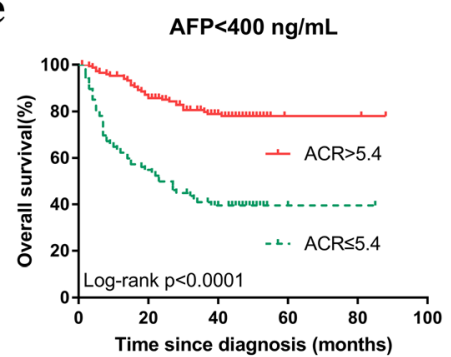

g

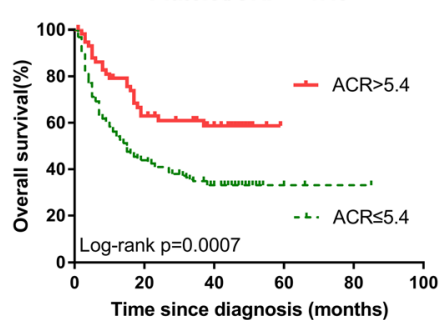

b

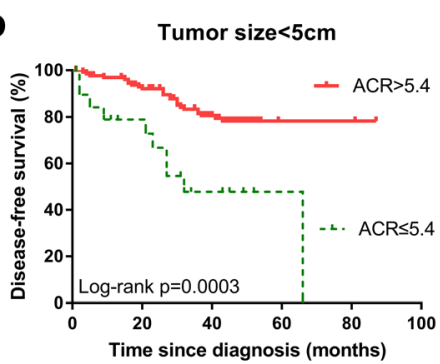

d

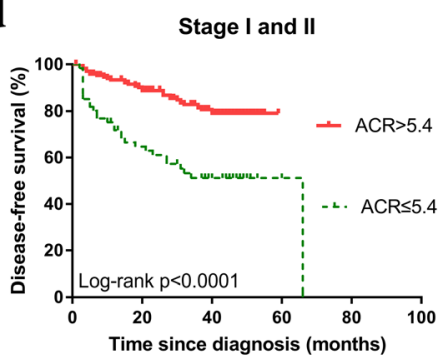

f

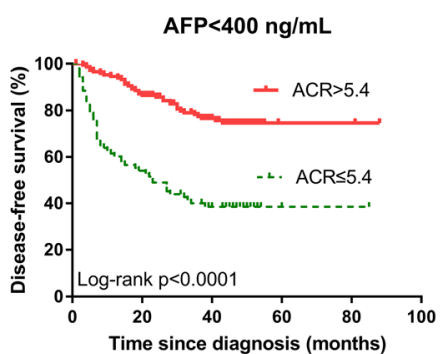

$\mathbf{h}$

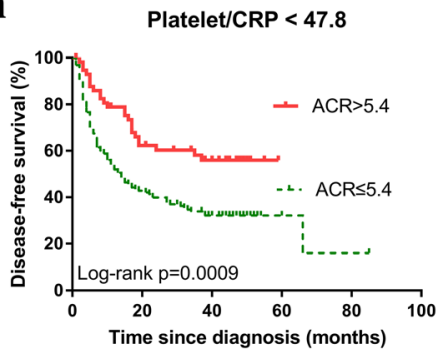

Fig. 4 Survival outcomes in patients with high ( $>5.4)$ and low $(\leq 5.4)$ ACR. a OS rate in the subgroup of tumor size $<5 \mathrm{~cm}$. b DFS rate in the subgroup of tumor size $<5 \mathrm{~cm}$. c OS rate in the subgroup of early stage (I or II). $\mathbf{d}$ DFS rate in the subgroup of early stage (I or II). e OS rate in the subgroup of AFP $<400 \mathrm{ng} / \mathrm{mL}$. $\mathbf{f}$ DFS rate in the subgroup of AFP $<400 \mathrm{ng} / \mathrm{mL}$. $\mathbf{g}$ OS rate in the subgroup of platelet $/$ CRP $<47.8$. $\mathbf{h}$ DFS rate in the subgroup of platelet / CRP $<47.8$

outcome in HCC patients. In the univariate analysis of OS and DFS, the significant prognostic parameters are tumor size, TNM stage, treatment exposure, serum AFP level, serum CRP level, serum albumin level, albumin / CRP ratio, and platelet / CRP ratio. In the multivariate analysis, the results indicated that tumor size, TNM stage, treatment exposure, serum AFP level, and albumin / CRP ratio were independent factors for $\mathrm{HCC}$ prognosis. The results indicated that treatment exposure, TNM stage, and tumor size, have higher HR value than ACR and AFP, which mean that they have a greater weight in representing its prognosis. However, these parameters were all subjective clinical features, while ACR and AFP were reliable markers that can be easily detected in peripheral blood. Accordingly, clinicians can make a preliminary judgment on the prognosis of HCC patients. We also analyzed the correlation between ACR and certain clinical parameters in subgroups. The results suggested that tumor size, TNM stage, treatment exposure, and serum AFP level are significantly correlated with ACR. Notably, patients underwent 
$\mathbf{a}$

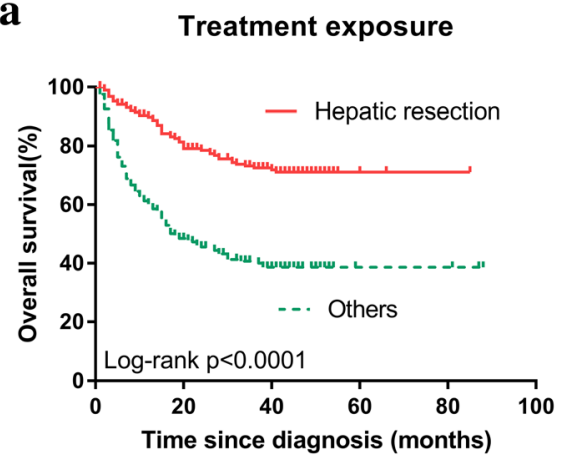

c

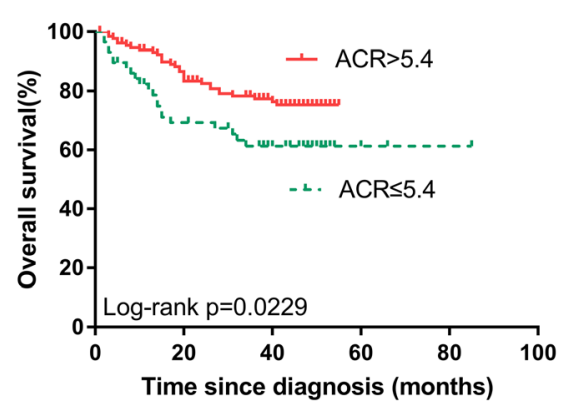

b

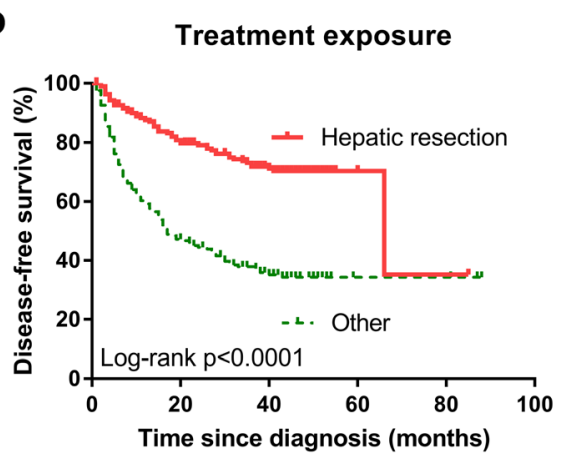

d

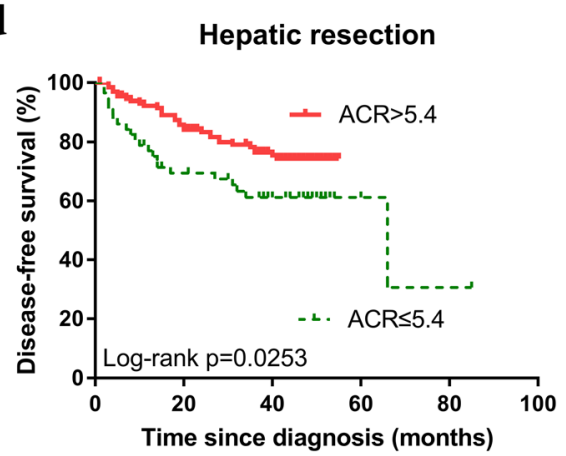

Fig. 5 Kaplan-Meier estimates of overall survival according to treatment exposure. Patients underwent hepatic resection had a significantly longer OS (a.), DFS (b) than those accepted other treatments $(p<0.0001)$. $\mathbf{c}$ OS rate in the subgroup of hepatic resection. $\mathbf{d}$ DFS rate in the subgroup of hepatic resection

hepatectomy seem had a better prognosis of OS and DFS, compared with other treatment options, including TACE, RFA, and chemotherapy. This may explain that hepatectomy was the main treatment option for HCC patients without cirrhosis [20]. El-Serag HB et al. had revealed that hepatectomy will be a priority for patients with early-stage, presenting a diameter of less than $5 \mathrm{~cm}$, or no more than three nodules, which is associated with an OS rate of $90 \%$ [24]. This also reveals that tumor size and TNM stage are correlated with OS.

Although previous studies have demonstrated that Neutrophil-to-Lymphocyte Ratio (NLR) was a reliable prognostic factor for OS in HCC patients [5, 25-27]. However, in the present study, no significant differences of NLR for OS in HCC patients was observed. As to ALT and AST, are commonly measured clinically as biomarkers for liver health. Our previous study has indicated that high preoperative AST concentrations can be used as prognostic factors for NSCLC when the cutoff value was $19 \mathrm{U} / \mathrm{L}$ [28]. Yet no association with the prognosis of HCC patients was shown in the present study. The possible explanations for the inconsistencies mentioned above may as follows: firstly, all the subjects involved in our study are Chinese, whereas other reports were different ethnic population; secondly, we performed the X-tile software to defined the optimal cut-off value, while other studies used ROC curves; last but not the least, the methods for detecting blood samples may be different, which could affect the results.

Serum AFP is currently the most commonly used as diagnosis and surveillance for hepatocellular carcinoma. However, serum AFP levels have low sensitivity (25 to $65 \%$ ), when using a cutoff point of $20 \mathrm{ng} / \mathrm{mL}$, for the detection of HCC. When it comes to HCC diagnosis, an AFP level of $400 \mathrm{ng} / \mathrm{mL}$ or higher also has great predictive value [29]. Despite its low sensitivity in the diagnosis of HCC, serum levels of AFP still served as an independent factor for $\mathrm{HCC}$ prognosis in our study. In the subgroup of AFP $<400 \mathrm{ng} / \mathrm{mL}$, the 1-, 3-, and 5year OS rate of the high ACR group were significantly higher than those of the low ACR group (95.4, 79.8, $77.9 \%$ vs $62.2,40.8,39.4 \%$, respectively; $p<0.0001$ ). However, An et al. demonstrated that pretreatment serum AFP with a cutoff point of $20 \mathrm{ng} / \mathrm{mL}$ served as a reliable predictor of prognosis among HCC patients underwent hepatectomy in a single-center cohort from China, which enrolled 251 HCC patients [30]. Therefore, whether serum AFP, with a cutoff point of $20 \mathrm{ng} / \mathrm{mL}$, can serve as another independent factor of OS for HCC patients in our cohort need further investigation.

A major strength of this study is that it firstly analyzed the ACR as a significant and independent factor for OS 
and DFS, involving 409 newly diagnosed HCC patients, retrospectively. However, it still has some limitations. First, the majority of cases included in this study were HCC patients with hepatitis B virus infection, and consequently, these results may not be applicable to patient cohorts from Western countries, who are usually dominated by hepatitis $C$ virus infection. Second, since it is a single-center cohort, this study needs a multi-center prospective design in a larger population to validate our results. Third, our study only analyzed the impact of some parameters on the OS and DFS in HCC patients, while other parameters such as prothrombin induced by vitamin K absence-II (PIVKA-II) [31], carcinoembryonic antigen (CEA) [32], the Barcelona Clinic Liver Cancer (BCLC) staging system [33], were not taken into account in this study.

\section{Conclusions}

From the above discussion, the conclusion can be reached that pretreatment ACR was a significant and independent factor for OS and DFS in patients with HCC. Pretreatment ACR was correlated with tumor size, TNM stage, treatment exposure, and serum AFP levels. Due to the mechanism of ACR in HCC patients is not clear, further prospective analyses should be conducted with larger population or multi-center cohorts.

\author{
Abbreviations \\ ACR: Albumin to C-reactive Protein Ratio; AFP: Alpha-fetoprotein; \\ ALB: Albumin; ALT: Alanine aminotransferase; AST: Aspartate \\ aminotransferase; BCLC: Barcelona Clinic Liver Cancer; \\ CEA: Carcinoembryonic antigen; CRP: C-reactive protein; DFS: Disease-free \\ survival; HBsAg: Hepatitis B surface antigen; HCC: Hepatocellular carcinoma; \\ NLR: Neutrophil-to-lymphocyte ratio; PCR: Platelet to C-reactive protein ratio; \\ PIVKA-II: Prothrombin induced by vitamin K absence-II; PLT: Platelet; \\ RFA: Radiofrequency ablation; TACE: Transcatheter arterial \\ chemoembolization
}

\section{Acknowledgments}

We gratefully acknowledge the staff at the clinical laboratory, Sun Yat-sen University Cancer Center for providing support to the research in this study.

\section{Authors' contributions}

MTW and HC conceived the study. MTW, SYH, ZQH, and YYZ made substantial contributions to data acquisition, SLC, LFL, and XH performed measurements and analyzed the data. MTW and SYH involved in drafting the manuscript. All authors have read and approved the final manuscript.

\section{Funding}

No funding was received.

\section{Availability of data and materials}

The datasets used and analyzed during the current study are available from the corresponding author on reasonable request.

\section{Ethics approval and consent to participate}

This study complied with the standards of the Declaration of Helsinki and current ethical guidelines. It was approved by the Sun Yat-sen University Cancer Center research ethics committee. All patients provided written informed consent for the collection and publication of their medical information at the first visit to our center, which was filed in their medical records.
Consent for publication

Not applicable.

\section{Competing interests}

The authors declare no conflict of interest. There are no financial and nonfinancial competing interests (political, personal, religious, ideological, academic, intellectual, commercial or any other) to declare in relation to this manuscript.

\section{Author details \\ 'Sun Yat-sen University Cancer Center, State Key Laboratory of Oncology in South China, Collaborative Innovation Center for Cancer Medicine, Guangzhou, China. ${ }^{2}$ Department of Laboratory Medicine, Sun Yat-sen University Cancer Center, Guangzhou, China. ${ }^{3}$ State Key Laboratory of Ophthalmology, Zhongshan Ophthalmic Center, Sun Yat-sen University, Guangzhou, China.}

Received: 24 October 2017 Accepted: 23 May 2019

Published online: 04 June 2019

\section{References}

1. Cancer [http://www.who.int/mediacentre/factsheets/fs297/en/].

2. McMillan DC. Systemic inflammation, nutritional status and survival in patients with cancer. Curr Opin Clin Nutr Metab Care. 2009;12(3).

3. Guthrie GJ. Charles Ka Fau - Roxburgh CSD, Roxburgh Cs Fau - Horgan PG, Horgan PG Fau - McMillan DC, McMillan Dc Fau - Clarke SJ, Clarke SJ: the systemic inflammation-based neutrophil-lymphocyte ratio: experience in patients with cancer. Crit Rev Oncol Hematol. 2013;88(1):218-30.

4. Chan SL, Chan AW, Chan AK, Jian P, Mo F, Chan CM, Mok K, Liu C, Chong CC, Chan AT, et al. Systematic evaluation of circulating inflammatory markers for hepatocellular carcinoma. Liver Int. 2017;37(2):280-9.

5. Goh BK, Kam JH, Lee SY, Chan CY, Allen JC, Jeyaraj P, Cheow PC, Chow PK, Ooi LL, Chung AY. Significance of neutrophil-to-lymphocyte ratio, plateletto-lymphocyte ratio and prognostic nutrition index as preoperative predictors of early mortality after liver resection for huge $(>/=10 \mathrm{~cm})$ hepatocellular carcinoma. J Surg Oncol. 2016;113(6):621-7.

6. Pinato DJ, Stebbing J Fau - Ishizuka M, Ishizuka M Fau khan SA, khan Sa Fau Wasan HS, Wasan Hs Fau north BV, north Bv Fau Kubota K, Kubota K Fau Sharma R, Sharma R A novel and validated prognostic index in hepatocellular carcinoma: the inflammation based index (IBI). J Hepatol 2012, 57(5):1013-1020.

7. Ji F, Liang Y, Fu SJ, Guo ZY, Shu M, Shen SL, Li SQ, Peng BG, Liang LJ, Hua YP. A novel and accurate predictor of survival for patients with hepatocellular carcinoma after surgical resection: the neutrophil to lymphocyte ratio (NLR) combined with the aspartate aminotransferase/ platelet count ratio index (APRI). BMC Cancer. 2016;16:137.

8. Hu B, Yang XR, Xu Y, Sun YF, Sun C, Guo W, Zhang X, Wang WM, Qiu SJ, Zhou J, et al. Systemic immune-inflammation index predicts prognosis of patients after curative resection for hepatocellular carcinoma. Clin Cancer Res. 2014;20(23):6212-22.

9. Nagaoka S, Yoshida T, Akiyoshi J, Akiba J, Torimura T, Adachi H, Kurogi J, Tajiri N, Inoue K, Niizeki T, et al. Serum C-reactive protein levels predict survival in hepatocellular carcinoma. Liver Int. 2007;27(8):1091-7.

10. Zhang XY, Zhang G, Jiang Y, Liu D, Li MZ, Zhong Q, Zeng SQ, Liu WL, Zeng MS. The prognostic value of serum C-reactive protein-bound serum amyloid a in early-stage lung cancer. Chinese journal of cancer. 2015;34(8):335-49.

11. Villasenor A, Flatt SW, Marinac C, Natarajan L, Pierce JP, Patterson RE. Postdiagnosis C-reactive protein and breast cancer survivorship: findings from the WHEL study. Cancer epidemiology, biomarkers \& prevention : a publication of the American Association for Cancer Research, cosponsored by the American Society of Preventive. Oncology. 2014;23(1):189-99.

12. Liao SG, Cheng HH, Lei Y. C-reactive protein is a prognostic marker for patients with castration-resistant prostate Cancer. Oncology research and treatment. 2016;39(5):266-71.

13. Kim EY, Yim HW, Park CH, Song KY. C-reactive protein can be an early predictor of postoperative complications after gastrectomy for gastric cancer. Surg Endosc. 2017;31(1):445-54.

14. Ishizuka M, Nagata H, Takagi K, Iwasaki Y, Shibuya N, Kubota K. Clinical significance of the $\mathrm{C}$-reactive protein to albumin ratio for survival after surgery for colorectal Cancer. Ann Surg Oncol. 2016;23(3):900-7. 
15. Cholongitas E, Papatheodoridis GV, Vangeli M, Terreni N, Patch D, Burroughs AK. Systematic review: the model for end-stage liver disease--should it replace child-Pugh's classification for assessing prognosis in cirrhosis? Aliment Pharmacol Ther. 2005;22(11-12):1079-89.

16. Bagirsakci E, Fau SE. Atabey N, Atabey N Fau - Erdal E, Erdal E Fau - Guerra V, Guerra V Fau - Carr Bl, Carr Bl: role of albumin in growth inhibition in hepatocellular carcinoma. Oncology. 2017;93(2):136-42.

17. Bruix J, Sherman M. Management of hepatocellular carcinoma. Hepatology. 2005;42(5):1208-36.

18. Sobin LH, Wittekind C. TNM classification of malignant Tumours. 6th ed. New York: Wiley-Liss; 2002.

19. Camp RL, Fau D-FM. Rimm DL, Rimm DL: X-tile: a new bio-informatics too for biomarker assessment and outcome-based cut-point optimization. Clinical cancer research : an official journal of the American Association for Cancer Research. 2004:10(21):7252-9.

20. Forner A. Llovet Jm Fau - Bruix J, Bruix J: Hepatocellular carcinoma. Lancet (London, England). 2012;379(9822):1245-55.

21. Jun CH, Ki HS, Lee KH, Park KJ, Park SY, Cho SB, Park CH, Joo YE, Kim HS, Choi SK, et al. Impact of serum C-reactive protein level on the prognosis of patients with hepatocellular carcinoma undergoing TACE. Clinical and molecular hepatology. 2013;19(1):70-7.

22. Forrest LM. McMillan dc Fau - McArdle CS, McArdle CS Fau - Angerson WJ, Angerson Wj Fau - Dunlop DJ, Dunlop DJ: evaluation of cumulative prognostic scores based on the systemic inflammatory response in patients with inoperable non-small-cell lung cancer. Br J Cancer. 2003;89(6):1028-30.

23. Kinoshita A, Onoda H, Imai N, Iwaku A, Oishi M, Tanaka K, Fushiya N, Koike $\mathrm{K}$, Nishino $\mathrm{H}$, Matsushima $\mathrm{M}$, et al. The addition of $\mathrm{C}$-reactive protein to validated staging systems improves their prognostic ability in patients with hepatocellular carcinoma. Oncology. 2014;86(5-6):308-17.

24. El-Serag HB. Hepatocellular carcinoma. N Engl J Med. 2011;365(12):1118-27.

25. Ji F, Liang Y, Fu SJ, Guo ZY, Shu M, Shen SL, Li SQ, Peng BG, Liang LJ, Hua YP. A novel and accurate predictor of survival for patients with hepatocellular carcinoma after surgical resection: the neutrophil to lymphocyte ratio (NLR) combined with the aspartate aminotransferase/ platelet count ratio index (APRI). BMC Cancer. 2016;16.

26. Aino H, Sumie S, Niizeki T, Kuromatsu R, Tajiri N, Nakano M, Satani M, Okamura S, Shimose S, Miyahara K, et al. The systemic inflammatory response as a prognostic factor for advanced hepatocellular carcinoma with extrahepatic metastasis. Mol Clin Oncol. 2016;5(1):83-8.

27. Oh BS, Jang JW, Kwon JH, You CR, Chung KW, Kay CS, Jung HS, Lee S. Prognostic value of $\mathrm{C}$-reactive protein and neutrophil-to-lymphocyte ratio in patients with hepatocellular carcinoma. BMC Cancer. 2013;13:78.

28. Chen SL, Xue N, Wu MT, Chen H, He X, Li JP, Liu WL, Dai SQ. Influence of preoperative serum aspartate aminotransferase (AST) level on the prognosis of patients with non-small cell lung Cancer. Int J Mol Sci. 2016;17(9).

29. El-Serag HB, Marrero JA, Rudolph L, Reddy KR. Diagnosis and treatment of hepatocellular carcinoma. Gastroenterology. 2008;134(6):1752-63.

30. Johnson PJ, Berhane S, Kagebayashi C, Satomura S, Teng M, Reeves HL, O'Beirne J, Fox R, Skowronska A, Palmer D, et al. Assessment of liver function in patients with hepatocellular carcinoma: a new evidence-based approach-the ALBI grade. Journal of clinical oncology : official journal of the American Society of Clinical Oncology. 2015;33(6):550-8.

31. Pote N, Cauchy F, Albuquerque M, Voitot H, Belghiti J, Castera L, Puy H, Bedossa P, Paradis V. Performance of PIVKA-II for early hepatocellular carcinoma diagnosis and prediction of microvascular invasion. J Hepatol. 2015;62(4):848-54.

32. Zhao J, Yan T, Bi X, Zhao H, Huang Z, Zhou J, Li Z, Li C, Cai J. Correlation of carcinoembryonic antigen with prognosis of hepatocellular carcinoma after hepatectomy. Zhonghua zhong liu za zhi [Chinese journal of oncology]. 2014;36(6):430-4

33. Hsu CY, Liu PH. A new treatment-integrated prognostic Nomogram of the Barcelona clinic liver Cancer system for hepatocellular carcinoma. Sci Rep. 2017;7(1):7914.

\section{Publisher's Note}

Springer Nature remains neutral with regard to jurisdictional claims in published maps and institutional affiliations.

Ready to submit your research? Choose BMC and benefit from:

- fast, convenient online submission

- thorough peer review by experienced researchers in your field

- rapid publication on acceptance

- support for research data, including large and complex data types

- gold Open Access which fosters wider collaboration and increased citations

- maximum visibility for your research: over $100 \mathrm{M}$ website views per year

At BMC, research is always in progress.

Learn more biomedcentral.com/submissions 